\title{
Attachment to Entrepreneur Brands: How the Entrepreneur Implements the Fronting Behavior?
}

\author{
Y. F. YU, H. C. WANG, K. LI \\ Economic and Management School of East China Jiaotong University, Jiangxi, China
}

\begin{abstract}
This study examines the impact that consumer-entrepreneur brand attachment has on opinions of entrepreneurs as endorsers of their companies. To test the hypothesis, we conducted a $2 \times 2$ factorial design manipulated attachment strength to the entrepreneur and fronting situation. Results found entrepreneur brand attachment significantly affects consumers' opinions of entrepreneurs, with no significant effect for fronting situation. Findings suggest that when consumers feel attached to a entrepreneur and view that whether positive or negative fronting behaviors, their opinions of the entrepreneur tend to remain positive. The results imply that entrepreneur brands and their top team would benefit from understanding relational and situational factors that trigger consumers' feelings of attachment.
\end{abstract}

KEYWORD: Consumer-Entrepreneur; Brand Attachment; Brand Endorsement; Fronting Behavior

\section{INTRODUCTION}

Recently, Zhang Chao Yang, the CEO of internet company Sohu, became the focus of the media. Owing to he was suspected infringing on $\mathrm{Xu} \mathrm{Xi}$ Yuan and Wang Xiao Fei's wedding. For a while, two different opinion groups appeared in public. Zhang Chao Yang's fans claimed the couple is contrived; as opposing groups lay claim Zhang is a snobbish businessman who betrayed friends for interest. The celebrity affaires turn out to be shouting match among fans. Why do people so interested in celebrities live far away from them? How is the relationship between consumer and celebrity?

The cooperation between brands and celebrities through brand endorsement is common phenomenon in marketing (Erdogan and Baker 1999). Among the factors affecting the corporate brand image, the entrepreneur who has unparalleled advantages as a natural "opinion leaders" (Gillin, 2007) or "super spokesperson" (Experian-Hitwise, 2007). Indeed, celebrity itself is considered to be a brand called celebrity brand, because they can be professionally managed and represent the characteristics of the brand $^{[20]}$ (Thomson 2006). Marketing community has generally accepted the view: Consumers are automatically associated with product brand. But few studies have examined the unique relationship between consumer and the celebrity brand, such as entrepreneurs.
This is an era for entrepreneur to go to the front line from the behind (Cai release, 2008). Due to the extending of Mass media in breadth and depth, there is an increasingly number of entrepreneurs enter to the public view. In addition, we live in a society dominated by economic development, economic figures, especially the successful economic figures naturally become a learning model and a barometer of society. The image of entrepreneurs that consumers familiar with will affect their evaluation of the corporate brand, thus will affect the brand consumption choice (Zhiyi, Wang Guangfu 2005).

Dramaturgy founder Goffman suggest that society and life is a big stage, members of the community as a performer on the stage play different roles in different sessions, According to whether the presence of a third party, we can divided the perform spaces into foreground and background. Interaction between entrepreneurs and consumers is similar to actors and audience on stage, Behaviors that have a direct impact on consumer is the entrepreneurs' fronting behavior and those behaviors being pushed to the public.

In the past, a lot of studies in marketing tried to introduce attachment theory to marketing research, especially the research of consumer brand relationships (Fournier 2005; Lumina S. Albert Leonard M. Horowitz, 2009; Yan, Dong Dahai, 2007; etc.). But few studies have examined the unique relationship between consumer and the celerbrity brand, such as entrepreneurs. Social 
psychology, sociology, mass media, popular culture and few studies in anthropology explored activities between fans and celebrities. These psychologists eventually attributed fan behavior to morbid psychology7 (Dietz et al.1991; Maltby et al 2006.), But the behavior that ordinary people participate in the celebrity-social was rarely mentioned. The purpose of this paper is to investigate how the attachment will affect consumers' overall evaluation of the entrepreneur, especially when entrepreneurs overexposed in front of the media.

\section{THEORETICAL OVERVIEW AND HYPOTHESES}

\subsection{Entrepreneurs and Consumers-celebrity Brand Attachment}

According to a conceptual model of brand value based on consumer, in which brand knowledge consists of brand awareness and brand image which is the key to creating brand value (Keller, 2008). Brand image refers to the specific brand awareness resulted from brand association in the consumers' mind (Keller 2008). Consumer's brand association of celebrity can be delivered the brand business through co-branding process (McCracken1989). Consumers have strong brand awareness of celebrity, because celebrities usually get a huge public awareness (Pringle and Binet 2005). Consumer's brand knowledge is organized by associated network. (Aaker 1991, 1996; Keller 1993). Although Aaker (1991) proposed the brand information classification based on the knowledge network of consumer, due to the inclusion of association without product, Keller (2008) classification is more suitable for celebrity brands. Celebrity brand association with celebrity attribute, their endorsement ads, their endorsement of the brand, endorsements attribute, as well as consumers' perception of the celebrities' experience. (Such as autographs, fan clubs, media articles and blog) (Jasmina Ilicic and Cynthia M. Webster 2010). The relationship between consumers and celebrities established through brand experience influence consumers' cognition, preference and choice (Aaker, 1991).

Bowlby (1969) presents attachment theory in terms of behavior perspective, Ainsworth (1978) developed the internal working model, which is adult attachment theory. Ainsworth (1978) believes that when people feel a strong attachment to each other, they want to be with attachment objects together even they will sacrifice themselves. Behavioral theory holds that people have an inherent habit that will be attracted by human faces. When the face becomes more and more familiar, the attachment relationship was strengthened (Blehar et al 1977; Schore 2000). Futhermore, people phsically tend to attach familiar people (Bowlby 1969; Muir et al 1994; Schore 2000). When a familiar object is a celebrity, it is difficult to distinguish the familiarity which is through the media or real social interaction (Restak 1991). In addition, research on consumer attachment celebrities (Thomson 2006) suggests that when consumers and celebrities form a meaningful relationship, they acknowledge they have different degrees attachment in the celebrities.

In terms of the relationship between consumer and celebrity brand, Bowlby's attachment theory (Bowlby 1979, 1980) indicated that there are different degree of attachment, the strong attachment will be accompanied by strong growth with the association, emotion, love and passion (Thomson, MacInnis and Park 2005). In addition, self-determination theory (Ryan and Deci 2000) suggested that the basic human needs related to motivation, including autonomy, relatedness and competence (ARC).Autonomy refers to the need to feel that their individual actions are self-selected, self-management and self-recognition. Relatedness refers to affiliation needs, and concerned by others. Competency refers to the individuals tend to seek a sense of achievement and challenge. The results showed that the strength of celebrity attachment has a direct relationship between the perceived of autonomy and relatedness, however, there is no direct relationship with competence (Thomson 2006).

Although the existing literature research are not integrated celebrity brands and celebrity endorsements, Evidences supported that consumer's view on celebrity endorsements is related to many celebrities' characteristics, which will affect consumer attachment to celebrities in turn. Therefore, proposed the following hypothesis:

H1: Better impression for entrepreneurs, the stronger attachment to entrepreneur brands.

\subsection{Entrepreneurs brand endorsement and the front line scene}

From the external view, entrepreneurs regard themselves as outstanding brand ambassadors, anthropomorphism the enterprise that means endow the uniquely human characteristics and features to enterprise (Bonfield, 1980; Fegley, 1981; Garbett, 1988), which have a significant impact on goods and services consumer (Mazur, 1999), investors and the company's reputation (Gaines, 2000).Excellent business leaders image will enhance corporate brand image, reduce corporate costs, generate premium effect, and good corporate brand image will increase corporate brand equity (Biel, 1992). Visiblely, business leader's image has become part of the corporate brand image. The entrepreneur's image is the public or consumers' fuzzy perception of their 
many attributes, which is affected by the words and actions of entrepreneurs (Miller et al., 1986).

This is a personalism age, and now many entrepreneurs move towards the front lines from behind, began to frequently appear on the front of the public and the media. These social wealth creators no longer played a conservative and lowkey role, they gradually realized that personal popularity is not only the affirmation of self social value, but also the important supplement of the corporate brand. These entrepreneurs frequently appeared on television, and some even become other companies' endorsers; the various biographies and autobiographies of successful people become best-seller in the bookstores, the star entrepreneurs columns and forums on websites flourishing; more and more financial publication at the news-stand; CCTV economic figures selection enjoy great popularity since it was established, even financial journalist and copywriter social status rose...... Their each and every action always attract the public's attention, their activities have not only belong to the individual, it has close relationship with the corporate and brand they represented. Be expert in building healthy and positive entrepreneur brand image, can make contribution to the corporate brand as corporate brand endorsement. From a realistic scenario, the consumers don't accept many entrepreneurs self-presentation behavior. On the one hand the correlation between the consumers and entrepreneurs is still very shallow; meanwhile, entrepreneurs brand endorsement strategy is similar to star endorsement strategy, firstly we should look at if their image, manners, speech fit corporate brand and consumer audiences.

For entrepreneurs and enterprises, excessive concentration of image promotion for the business leaders is dangerous (Budd, 1990; Dilenschneider, 1990; Grunig, 1993; Hutton, 1999). Firstly, entrepreneur own personality and style shaped the entire enterprise personality (Garbett, 1988), the entrepreneur's image reflects entire enterprise's image (Gary, 1986). Secondly, because of the media tend to focus on individual senior leaders, entrepreneur replaced enterprise and organization (Gansh, 1979; Gitlin, 1980; Schudson, 1978). Finally, compared with the positive information, people are more inclined to focus on the negative information, and under the same circumstances, negative information have greater impact on people (Skowronski, 1989; Huang et al., 2010).

Apply consumer-celebrity brand attachment to entrepreneurs endorsement scenario, we believed that consumer perception of celebrities is not only related to celebrity brand attachment, but also related to the degree of entrepreneur's front-line behaviors. Thus, we proposed the following hypothesis:
$\mathrm{H} 2$ : The stronger consumer-entrepreneur brand attachment, the better overall evaluation of the entrepreneur.

H3: Compared to high-key and aggressive entrepreneurs, low-key and restrained entrepreneurs will gain better overall evaluation.

We summarized above in Figure 1.

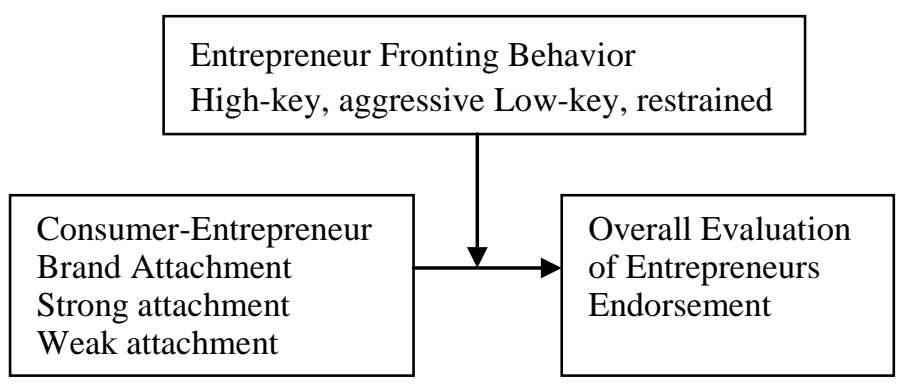

Fig.1: research model

\section{RESEARCH METHODS}

\subsection{Study Design}

To test the hypothesis, we conducted a $2 * 2$ factor design manipulate entrepreneurs attachment strength (strong or weak) and the fronting condition (high-key or low-key). Thus, four experimental situations were created:

1. Strong attachment, low-key fronting;

2. Strong attachment, high-key fronting;

3. Weak attachment, low-key fronting;

4. Weak attachment, high-key fronting.

\subsection{Measurement}

We manipulate attachment strength by using two entrepreneurs. Two well-known entrepreneurs: China United Network Communications Group cochairman Chang Xiaobing and Peking Yanjing Beer Group chairman Li Fucheng. When we started the article, they were both well-known entrepreneurs on 2010 China's top ten economic figures list. Extensive network search found that there is little controversy about them because of two of them have not published a book or attended the TV talent show. In pretests of 28 students found that two of them both have a high degree of familiarity (mean 5.6 VS 5.5), however, there are differences between the attachment points, Chang Xiaobing gets 4.97 while Li Fucheng gets 2.48. Therefore, Chang Xiaobing is used in a strong attachment scenario, while $\mathrm{Li}$ Fucheng be used in a weak attachment scenario.

The booklet of fronting behaviors contains 12 kinds of fronting behaviors. Under the low-key fronting behavior situation, the booklet of fronting contains a test of fronting scene in which the entrepreneur is either Chang Xiao Bing or $\mathrm{Li} \mathrm{Fu}$ Cheng. There are other five well-known 
entrepreneurs attended the other fronting activities while another six fronting behaviors are not attended by entrepreneurs. In a high-key fronting behavior, participants were asked to reading the same three kinds of fronting scenarios attended by Chang Xiao Bing or Li Fu Cheng. The remaining nine kinds of fronting situations attended by other three entrepreneurs.

The measurement scale for attachment directly uses Thomson (2006) approach. The measurement scale for consumer's evaluation of entrepreneurs endorsement uses Till \& Shimp scales, according to the need we change some words of it . In addition, the overall rating scale of entrepreneurs merged the preference of the measurement scale which used by Mowen and Brown (1981). All constructs of Entrepreneur overall rating (good VS positive VS pleasing VS lovely) have a high reliability $($ Cronbach's alpha $=0.965)$.

\subsection{Procedure}

239 undergraduate students participate in this experiment who have learned marketing course before. First, the paticipants were asked to browse a photo of Chang Xiaobing or Li Fucheng, then evaluate their degree of attachment to the entrepreneur. Next, participants read the booklet of fronting behavior. Under the low-key fronting situation participants were asked to read a particulous text in which assum that the entrepreneurs were invited to attend an event. Then they evaluate their overall impression of the entrepreneurs. Under the high-key fronting situation, participants were visible to the three virtual events that attended by entrepreneurs: a talent show guests, a book signing site and a charity scene. Then participants assess their overall impression of the entrepreneur again.

\section{RESULTS}

We analysis overall evaluation of entrepreneurs endorsement and the attachment of every fronting situation. $\mathrm{T}$ test showed a significant difference in the attachment degree of Chang Xiaobing and $\mathrm{Li}$ Fucheng, no matter it is a high-key fronting or a low-key fronting (Chang Xiaobing (mean $=2.97$, sd $=0.64)$ VS Li Fucheng (mean = 2.09, sd = 0.96)). Positive correlation between the degree of attachment and entrepreneurs endorsement overall evaluation (Pearson's $\mathrm{r}=0.401, \mathrm{p}<0.05$ ). In addition, compared with the weak attachment context, the overall evaluation of entrepreneurs endorsement no matter high-key fronting or low-key fronting is relatively high in strong attachment situations.

\subsection{An overall evaluation of entrepreneurs endorsement.}

$2 \times 2$ interclass variance test the main effects and interaction effects. Fronting scene and attachment strength as independent variables and an overall evaluation of entrepreneurs endorsement as dependent variable. The results (see Table 1) show that the main effect of overall evaluation is significant, while the fronting scene is not significant. In other words, the overall evaluation of entrepreneurs endorsement is affected by the attachment degree but make no difference whether entrepreneurs is high-key fronting or low-key fronting.

Table. 1 the main effects and interaction effects

\begin{tabular}{|l|l|c|c|c|}
\hline $\begin{array}{l}\text { Dependent } \\
\text { variable }\end{array}$ & $\begin{array}{c}\text { Mean } \\
\text { Square }\end{array}$ & F & Sig. \\
\hline \multirow{2}{*}{$\begin{array}{l}\text { An overall } \\
\text { Evaluation of } \\
\text { entrepreneurs } \\
\text { endorsement }\end{array}$} & attachment & 130.970 & 96.903 & .000 \\
\cline { 2 - 5 } & Low-key VS high-key & .268 & .201 & .698 \\
\cline { 2 - 5 } & $\begin{array}{l}\text { attachment× ( Low-key } \\
\text { high-key interaction) }\end{array}$ & 3.359 & 2.490 & .115 \\
\hline
\end{tabular}

\subsection{Moderating Effect of fronting scene}

Figure 2 shows that the participates who were in a strong attachment context have a higher overall evaluation of entrepreneur endorsement than in a weak attachment context no matter what the fronting scene(high-key or low-key). This means that when consumers are more attached to the entrepreneur even though he has a high-key fronting behavior, the overall evaluation of entrepreneur endorsement will not fall. Despite there is no significant interaction, the results noted that the entrepreneurs of a high-key fronting has a higher overall evaluation entrepreneurs endorsement in a weak attachment contexts.

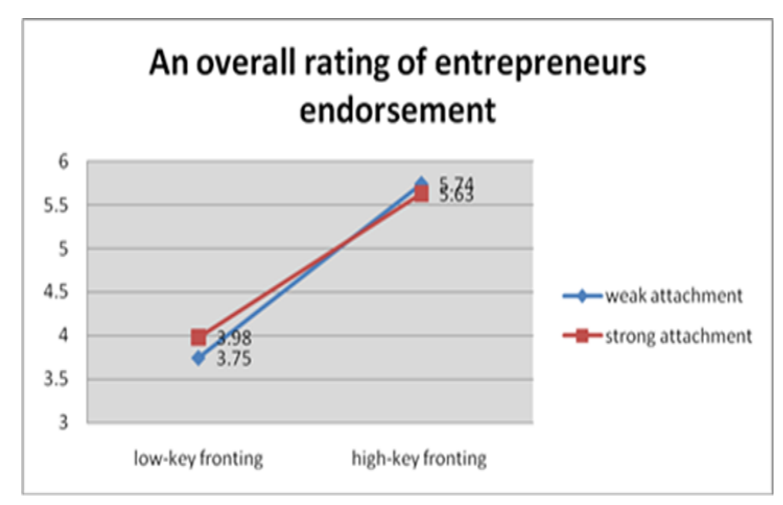

Fig.2: Overall evaluation of entrepreneur endorsement

\section{DISCUSSION}

\subsection{Research results and significance}

By empirical methods, the study explored how consumer-entrepreneur brand attachment impact on 
overall evaluation of entrepreneurs endorsement, particularly in the background of entrepreneur fronting behavior. Based on the above results, we get the following conclusion: In situations with weak attachment, the overall evaluation of entrepreneurs endorsement to the high-key entrepreneur fronting behavior is better than lowkey entrepreneur fronting behavior. In situations with strong attachment, whether its high-key or lowkey entrepreneur fronting behavior, the overall evaluation of entrepreneurs endorsement are better than weak attachment situations.

A huge challenge corporate facing is: identifying suitable inheritor. In addition, it is also essential for entrepreneurs that they should effectively manage their brand image. As a entrepreneurs management team, they should carefully select the fronting behavior. The results show that if consumer has strong attachment to entrepreneur brands, whether the fronting behavior is high-key or low-key, consumers' overall evaluation was better than in the weak attachment situations. Even more interesting is that there is a slight promotion of overall evaluation in high-key fronting behavior in the weak attachment situations. Future research should examine the relationship between the weak consumer-entrepreneur brand attachment and highkey fronting behavior. These findings are helpful to clarify which circumstances will lead to the negative outcome of high-key fronting behavior. Which is important for entrepreneurs and management teams.

\subsection{Limitations and future research directions}

In this study, the following aspects need to be improved. Firstly, although the selected entrepreneurs from different industries, in fact, it doesn't represent the characteristics of entrepreneurs in all industry which limited the conclusions extend in other industries. Secondly, quantitative classification about fronting behavior should be improve, since high-key and low-key is qualitative terms, although we classified by the number of fronting behavior, but it can not represent complete connotation of fronting behavior. Therefore, the correct understanding of fronting behavior content will be able to develop the conclusions of this stud . Thirdly, consumer's evaluation of entrepreneurs endorsement affected by many factors, such as the age, different development crisis they facing, different focus on attachment relationships Levinson's (1986). Fourthly, there is a slight promotion of overall evaluation in high-key fronting behavior in the weak attachment situations. Future research should examine relationship between weak consumer brand attachment and aggressive fronting behavior.

\section{ACKNOWLEDGEMENTS}

The current research is supported by the National Natural Science Foundation of China (Grand No. 71362003: Entrepreneur Brand Attachment: Measurement Dimension, Influencing Factors and Mechanism Research). Many references had to be deleted to shorten this revies, and I apologize to authors and readers for work that could not be cited.

\section{REFERENCES}

[1] Aaker, D. A., Myers, J. G., 1987. Advertising Management, 3rd ed., New Jersey: Prentice-Hall.

[2] Ainsworth, M. (1978). Patterns of attachment: A psychological study of the strange situation. Hillsdale, NJ: Lawrence Erlbaum Associates.

[3] Bowlby, J. (1969). Attachment and loss, Vol. 1, attachment. London

[4] Bowlby, J., 1979. The Making and Breaking of Affectional Bonds, London: Tavistock.

[5] Bowlby, J., 1980. Loss: Sadness and Depression, New York: Basic Books.

[6] Deci, E. L., Ryan, R. M., 2000. The 'What' and 'Why' of Goal Pursuits: needs and self determination of behaviour. Psychological Inquiry 11 (4), 227-268.

[7] Dietz, P. E., Matthews, D. B., Van Duyne, C., Martell, D. A., Parry, C., Stewart, T., et al. (1991). Threatening and otherwise inappropriate letters to Hollywood celebrities. Journal of Forensic Sciences, 36(1), 185-209.

[8] Erdogan, B., Baker, M., 1999. Celebrity Endorsement: Advertising agency managers' perspective Cyber-Journal of Sports Marketing. Accessed on 21 Dec 2006

[9] Erikson, E. H. (1968). Youth and crisis. New York: WW Norton and Co.

[10]Fournier, S. M. (1998), "Consumers and their brands: developing relationship theory in consumer research", Journal of Consumer Research, Vol.24, pp.43 73.

[11]Garbett, T. (1988), How to build a corporation's identity and project its image, Lexington, MA: Lexington.

[12]Gary, J. G. JR. (1986), Managing the corporate image, Westport, CT: Quorum.

[13]Gayle S. Stever (2011), Fan Behavior and Lifespan Development Theory: Explaining Para-social and Social Attachment to Celebrities. Journal of Adult Dev (18):1-7.

[14]Gitlin, T. (1980), The whole world is watching, Berkeley, CA: University of California Press.

[15]Grunig, J. E. (1993), "Image and substance: From symbolic to behavioral relationships", Public Relations Review, Vol.19, No.2, pp.121 139.

[16]Keller, K L. (1993), J. Conceptualizing, measuring, and managing customer based brand equity Journal of Marketing, 57 (Jan.): 1- 22.

[17]Keller, K. L. (1998), Strategic Brand Management, Upper Saddle River, NJ: Prentice Hall.

[18]Levinson, D. J. (1986). A conception of adult development. American Psychologist, 41(1), 3-13.

[19]Schore, A. N. (2000). Attachment and the regulation of the right brain. Attachment and Human Development, 2(1), 23-47.

[20]Thomson, M., 2006. Human Brands: Investigating antecedents to consumers' strong attachments to celebrities. Journal of Marketing 70 (July), 104-119. 